\title{
Transistor needle chip for recording in brain tissue
}

\author{
Florian Felderer • Peter Fromherz
}

Received: 1 April 2011 / Accepted: 6 April 2011 / Published online: 5 May 2011

(C) The Author(s) 2011. This article is published with open access at Springerlink.com

\begin{abstract}
We report on a proof-of-principle experiment for the direct interfacing of transistors with intact brain tissue. A transistor needle chip (TNC) with a $\mathrm{TiO}_{2}$ surface is fabricated from a silicon-on-insulator wafer and impaled into an acute brain slice cut from hippocampus of the rat. While stimulating the Schaffer collateral, a local field potential is recorded in stratum radiatum of the CA1 region with fieldeffect transistors in the central part of the slice where the tissue is not damaged by the cutting process. After the impalement, the signal amplitude is small. Within an hour, it increases to a stable level around $-2 \mathrm{mV}$ as is recorded with a conventional micropipette electrode. The recovery indicates that the tissue is able to adapt to the impaled chip. Upon repeated impalements at the same position, the large signal is observed without delay. A profile of the transistor signal across the slice is due to the boundary conditions of a brain slice with both surfaces held near ground potential. The experiments with the TNC prototype are a basis for the development of silicon needle chips with a large multi-transistor array (MTA) for applications in brain-computer interfacing.
\end{abstract}

\section{Introduction}

The electrical interfacing of brain tissue is a topical issue in brain physiology, neuroprosthetics and brain-computer interfacing [1-3]. Generally, metal electrodes are used as thin wires $[4,5]$ or as planar contacts on a silicon substrate

F. Felderer · P. Fromherz $(\bowtie)$

Department of Membrane and Neurophysics,

Max Planck Institute for Biochemistry, Am Klopferspitz 18,

82152 Martinsried-München, Germany

e-mail: fromherz@biochem.mpg.de

Fax: +49-89-85782822
[6-10]. Though recordings of local field potentials as well as of single unit activity are being used to control prosthetic devices [1, 2], further development and optimization of the tissue/electrode interaction is required to achieve a reliable long-term interfacing. In experiments with cultured neurons and brain slices it has been demonstrated that silicon chips with an electrolyte-oxide-semiconductor (EOS) contact can be used successfully for the interfacing of mammalian neurons, using EOS transistors for recording and EOS capacitors for stimulation [11-14]. In the present study we show that transistor recording is possible also with a chip geometry that will allow the interfacing of brain tissue in a living animal. In that approach it was necessary to combine the processing of EOS field-effect transistors (FETs) $[15,16]$ with the micromachining of silicon needle chips [8] and with the coating by titanium dioxide as a biocompatible layer $[13,17]$. The prototypes of the transistor needle chips (TNCs) are tested for their functionality in acute brain slices from rat hippocampus.

\section{Materials and methods}

\subsection{Chips}

The TNCs are fabricated from silicon-on-insulator (SOI) wafers (4 in.) with 100- $\mu \mathrm{m}$ n-type silicon (1-10 $\Omega \mathrm{cm}$ ) and $2-\mu \mathrm{m} \mathrm{SiO}_{2}$ on a $400-\mu \mathrm{m}$-thick silicon substrate (SiMat, Landsberg, Germany). A TNC consists of two parts, a needle (2-mm long) with an array of four transistors (gate area $10 \mu \mathrm{m} \times 10 \mu \mathrm{m}$, pitch $80 \mu \mathrm{m})$ and a contact plate with the bond pads. An electron micrograph is shown in Fig. 1. For stability reasons, the needles of the prototype series are relatively massive with a thickness of $100 \mu \mathrm{m}$ and a width of $360 \mu \mathrm{m}$. A rather blunt shape of the tip is fabricated (Fig. 1) 


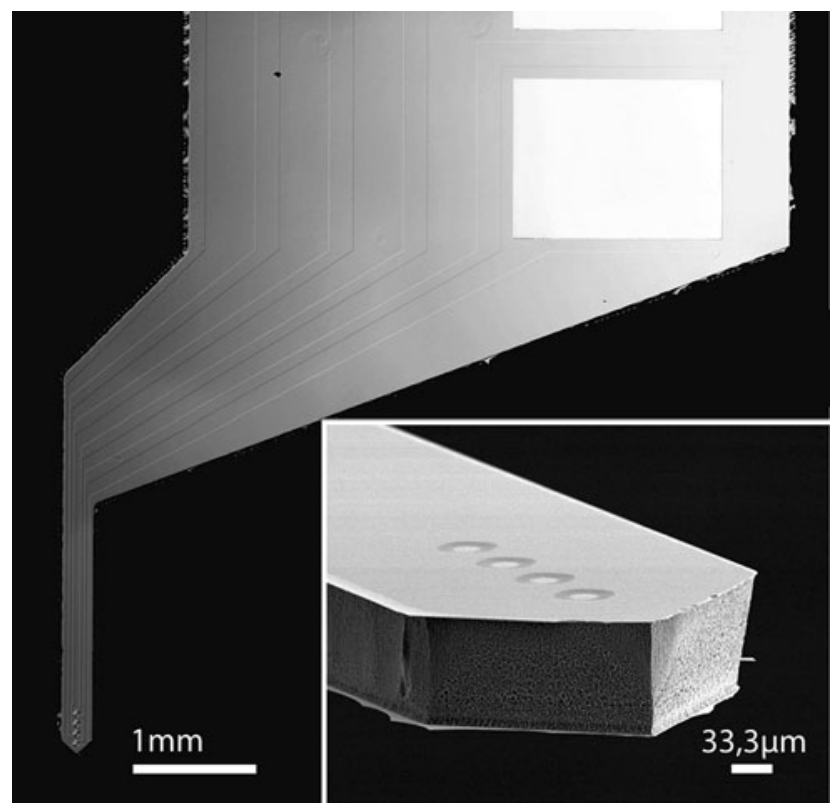

Fig. 1 Electron micrograph of a transistor needle chip (TNC). The picture shows the needle with four transistors and a portion of the contact plate with one of the metalized bond pads. The thickness of the needle is $100 \mu \mathrm{m}$. The vertical walls are obtained by a Bosch-like plasma process

in order to place the transistors close to the tip. Thinner needles and sharper tips may be chosen in the future. The contact plate is $500-\mu \mathrm{m}$ thick, $5-\mathrm{mm}$ wide and $10-\mathrm{mm}$ long. Its edge is displaced with respect to the needle in order to allow a visual control of the impalement.

The EOSFETs are fabricated on the thin silicon layer of the SOI wafers in analogy to the processing of simple Si wafers $[15,16]$. A mask oxide $(650 \mathrm{~nm})$ is formed by wet thermal oxidation. The areas of the sources and the drains with their connections to the bond pads are opened by wet etching (12.5\% buffered fluoric acid). They are coated with a 20 -nm scattering oxide by a rapid thermal process $\left(1130^{\circ} \mathrm{C}, 3 \mathrm{slm} \mathrm{O}_{2}\right.$ ) (AST100NT, Mattson Technology, Fremont, CA) and doped with boron by ion implantation $(6.5 \times$ $10^{15} \mathrm{~cm}^{-2}, 50 \mathrm{keV}$ ) (Ion Beam Service, 13790 Peynier, France). The oxide on the front and the back of the wafer is removed by wet etching. A thin $(11 \mathrm{~nm})$ high-quality oxide is formed by a rapid thermal process $\left(1130^{\circ} \mathrm{C}, 3 \operatorname{sim~} \mathrm{O}_{2}\right)$ and a field oxide $(1.4 \mu \mathrm{m})$ is deposited by plasma enhanced chemical vapor deposition (PECVD) $\left(300^{\circ} \mathrm{C}, 170 \mathrm{slm} \mathrm{SiH}_{4}\right.$ with $2 \% \mathrm{~N}_{2}, 720 \mathrm{slm} \mathrm{N}_{2} \mathrm{O}, 1000$ mTorr) (Plasmalab 80+, Oxford Instruments, Abingdon, UK). Circular windows (diameter $20 \mu \mathrm{m})$ are etched for the gates; a gate oxide $(11 \mathrm{~nm})$ is formed by a rapid thermal process $\left(1130^{\circ} \mathrm{C}, 3 \operatorname{sim} \mathrm{O}_{2}\right)$ and annealed in a hydrogen atmosphere $\left(490^{\circ} \mathrm{C}, 2 \mathrm{~min}\right)$. A layer of $\mathrm{TiO}_{2}(13 \mathrm{~nm})$ is deposited by atomic layer deposition (ALD) (ASM, Helsinki, Finland) to enhance the chemical stability of the TNC in the tissue and to improve the biocompatibility $[13,17]$. On the bond pads, the $\mathrm{TiO}_{2}$ is removed by plasma etching (RIE Plasmalab 80+) (1:1 $\mathrm{CHF}_{3} / \mathrm{Ar}, 30 / 30 \mathrm{sccm}, 50$ mTorr) and the $\mathrm{SiO}_{2}$ by wet etching. The bond pads are metalized by sputtering with an $\mathrm{Al} / \mathrm{Si}$ (6\%) alloy $(150 \mathrm{~nm})$.

The needles and contact plates are fabricated by a series of etching processes. In contrast to the silicon needles with planar metal electrodes [8], care has to be taken that the front side of the wafer with the transistors is protected during the whole procedure. At first, a mask oxide $(1.4 \mu \mathrm{m})$ is formed on the back of the SOI wafer by PECVD to cover the region of the contact plates. In that process the front side is protected by a layer of polyimide $(16 \mu \mathrm{m})$ (PI $2556 \mathrm{HD}$ MicroSystems, Neu-Isenburg, Germany). Then the silicon substrate in the region of the needles is removed by chemical etching with an EDP-S solution (160 g pyrocatechol, $3 \mathrm{~g}$ pyrazine and $66 \mathrm{~g}$ water per liter ethylenediamine) [18]. In that process the wafer is mounted in a special holder (AMMT GmbH, Frankenthal, Germany) that shields the front side. After removing the protecting polyimide, the front side is coated with a mask layer of polyimide $(32 \mu \mathrm{m})$ to cover the TNCs. Around the TNCs, the $\mathrm{TiO}_{2}$ is removed by plasma etching (1:1 $\left.\mathrm{CHF}_{3} / \mathrm{Ar}, 30 / 30 \mathrm{sccm}, 50 \mathrm{mTorr}\right)$ and the silicon by a Bosch-like process $[19,20]$ with periods in a $\mathrm{SF}_{6} / \mathrm{O}_{2}$ plasma (50 sccm/10 sccm, 50 mTorr, $\left.30 \mathrm{~s}\right)$, which remove the silicon, and with passivation periods in a $\mathrm{CHF}_{3}$ plasma (50 sccm, $100 \mathrm{mTorr}, 30 \mathrm{~s}$ ). This process also removes the field oxide and the $2-\mu \mathrm{m} \mathrm{SiO}_{2}$ of the SOI wafer. On the back of the needles, the 2- $\mu$ m-thick $\mathrm{SiO}_{2}$ layer remains as an insulation. With the prototype series of TNCs, no additional coating is used to insulate the side walls. In a later series, the ALD process was applied after the etching of the needles such that the side walls are coated by $\mathrm{TiO}_{2}$; wire bonding was achieved through the $\mathrm{TiO}_{2}$ (Schneckenburger and Fromherz, unpublished). After the processing, the contact plates remain connected to the wafer by a narrow bridge which is broken when a TNC is used. The TNCs are glued to a printed circuit board and wire bonded. The bond contacts are insulated with a silicone adhesive.

\subsection{Brain slices}

Acute brain slices from rat hippocampus are prepared by standard techniques [21,22]. All animal procedures are performed in accordance with national and EU law. In short: male Wistar rats (25 days old) are anaesthetized with isoflurane and decapitated. After quick dissection, the brain is placed in ice-cold artificial cerebrospinal fluid (ACSF) (124 mM NaCl, $3 \mathrm{mM} \mathrm{KCl}, 1.25 \mathrm{mM} \mathrm{KH} 2 \mathrm{PO}_{4}, 2 \mathrm{mM}$ $\mathrm{MgSO}_{4}, 26 \mathrm{mM} \mathrm{NaHCO} 3,2.5 \mathrm{mM} \mathrm{CaCl} 2,10 \mathrm{mM}$ glucose) that is aerated with $95 \% \mathrm{O}_{2} / 5 \% \mathrm{CO}_{2}$. The hippocampi are isolated and stabilized by an agar block in cold ACSF; their dorsal region is cut into 800- $\mu$ m-thick transverse slices (Vibratom VT 1000S, Leica) that are kept for $2 \mathrm{~h}$ at room temperature in a perspex dish that is perfused with aerated ACSF. 


\subsection{Set-up}

A membrane (PICMOR50, Millipore, Billerica, MA) is used as a support for the brain slices in a perspex chamber of the set-up. It is coated with an agar layer (about $1 \mathrm{~mm}$ ) to prevent damage to the TNCs when they are impaled. After perfusing the chamber with aerated ACSF for $15 \mathrm{~min}$, a slice is clamped to the agar by a nylon net (mesh size $700 \mu \mathrm{m})$. With further perfusion, all experiments are performed at room temperature. The geometry of the set-up is sketched in Fig. 2A. A slice with the nylon net, an impaled tungsten electrode and an impaled TNC is shown in Fig. 2B, and the same slice is depicted Fig. $2 \mathrm{C}$ after removal of the net, the electrode and the chip.

A monopolar tungsten electrode (AMS 5753, Science Products, Hofheim, Germany) is impaled into the Schaffer collaterals using a programmable micromanipulator (Type 5171, Eppendorf, Hamburg, Germany). The slice is stimulated by a cathodic current using a stimulus isolator (A360D, WPI, Berlin, Germany). Pulses with an amplitude of $100 \mu \mathrm{A}$ and a duration of $100 \mu$ s reliably evoke excitatory postsynaptic potentials in the CA1 region.

For comparative experiments, sharp micropipettes with a chlorinated silver wire (borosilicate glass, $0.5-\mu \mathrm{m}$ tip diameter, $3 \mathrm{M} \mathrm{NaCl}, 10-\mathrm{M} \Omega$ resistance) are used to record the field potentials (Axoclamp 2B, Axon instruments, Foster City, CA). The micropipette electrode is attached to a programmable micromanipulator. It is impaled into stratum radiatum of the CA1 region without a TNC and also in combination with a TNC and a close contact of the pipette tip and one of the transistors. The bath is held at ground potential with two $\mathrm{Ag} / \mathrm{AgCl}$ electrodes (In Vivo Metric, Healdsburg, CA) near the inlet and the outlet of the chamber. The signals are low-pass filtered at $1 \mathrm{kHz}$.

Before impaling a TNC, the operating point of all four transistors is chosen. About $+0.25 \mathrm{~V}$ is applied to the sources and to bulk silicon with respect to the $\mathrm{Ag} / \mathrm{AgCl}$ electrode in the bath (gate voltage $-0.25 \mathrm{~V}$ ). About $-0.25 \mathrm{~V}$ is applied to the drain with respect to the source. The drain current is around $-6 \mu \mathrm{A}$. The chips are connected to a custombuilt amplifier and the signals are low-pass filtered at $3 \mathrm{kHz}$. The drain current is calibrated by applying voltage pulses of $1 \mathrm{mV}$ to the bath electrode. With the relation $\delta I_{D}^{\mathrm{cal}}=$ $g_{m} \delta V_{\mathrm{bath}}^{\mathrm{cal}}$, transconductances in a range of $g_{m}=15 \mu \mathrm{S}$ are obtained. In the recording experiments, the field potential is evaluated with the relation $\varphi=\delta I_{D} / g_{m}$. After the calibration, a TNC is impaled into stratum radiatum of the CA1 region using a programmable micromanipulator. The transistors are facing the incoming Schaffer collateral. The procedures of the impalement are described in the results section.
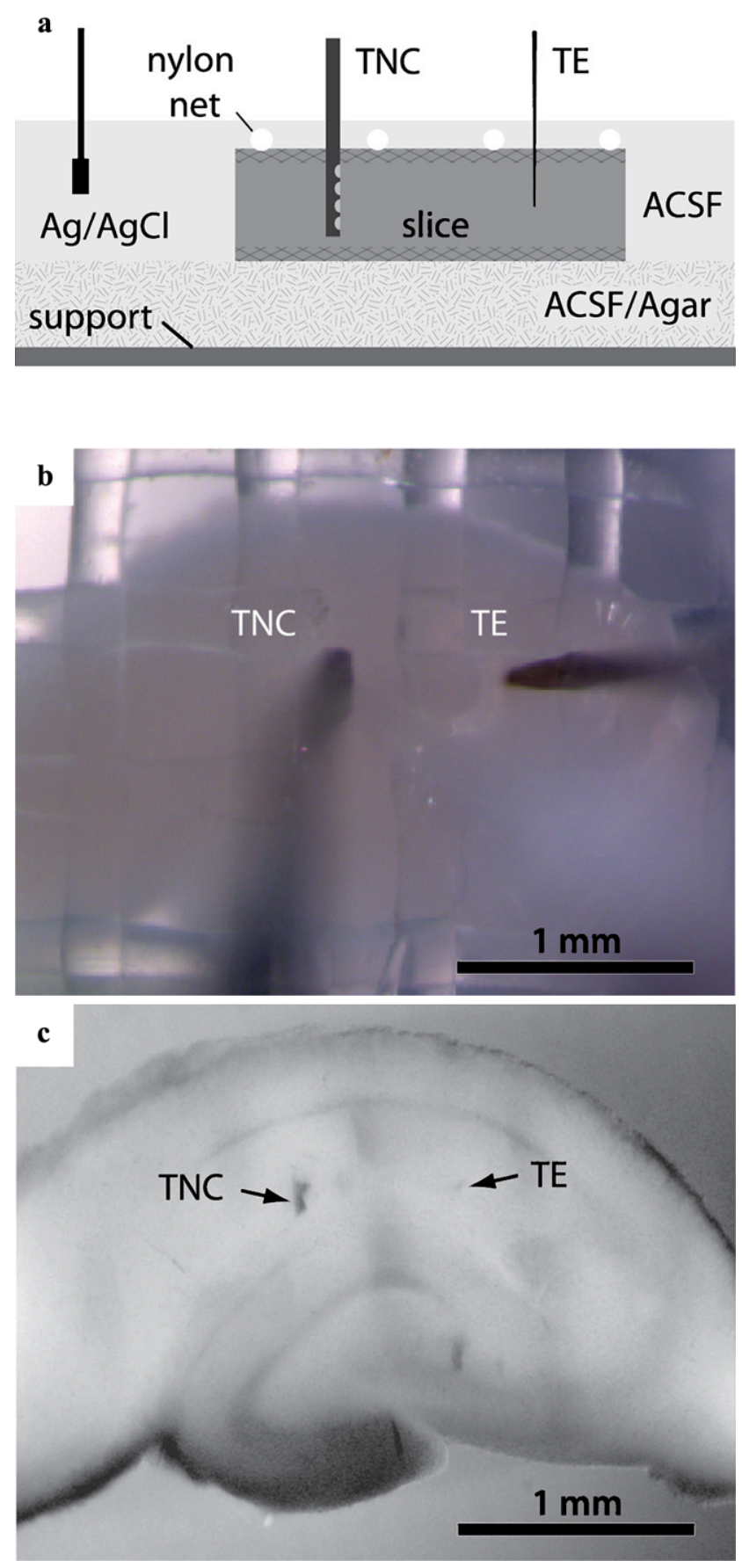

Fig. 2 Set-up of transistor needle chip (TNC) with an acute brain slice from rat hippocampus. (A) Schematic cross section. A nylon net clamps the slice on an agar layer on top of a support. The artificial cerebrospinal fluid (ACSF) is held at ground potential with an $\mathrm{Ag} / \mathrm{AgCl}$ electrode. The slice is stimulated with a tungsten electrode (TE) in the Schaffer collaterals. Local field potentials are recorded in stratum radiatum of the CA1 region with a TNC. (B) Micrograph of a slice with nylon net, impaled TE, and impaled TNC. (C) Micrograph of the same slice after the removal of the net as well as of the TE and of the TNC at the positions that are marked by the arrows. The picture was taken 10 min after the end of an experiment 


\section{Results and discussion}

\subsection{Recovery of field potential}

We studied transistor recordings with a TNC in acute brain slices from rat hippocampus after fast impalements $(500 \mu \mathrm{m} / \mathrm{s})$ of the needle into stratum radiatum of the CA1 region and stimulation of the Schaffer collaterals with the tungsten electrode. An example is shown in Fig. 3. The first EOSFET of the array was positioned at a depth of about $200 \mu \mathrm{m}$ in an $800-\mu \mathrm{m}$-thick slice. The stimulation pulses were applied at intervals of $5 \mathrm{~s}$ for one minute and with intervals of $10 \mathrm{~s}$ for a further $25 \mathrm{~min}$. Figure 3A shows recordings of the first EOSFET. Immediately after the impalement, a fiber volley is observed with a delay of about $3 \mathrm{~ms}$ after the stimulation artifact (time 0). Subsequently, a negativevoltage transient appears that has the typical shape of a local field potential due to excitatory synaptic currents [23]. The amplitude is about $-0.8 \mathrm{mV}$ at a delay of about $8 \mathrm{~ms}$. Further recordings are depicted in Fig. 3A for stimulations at 2, 9 and 26 min after the impalement. The amplitude decreases within two minutes and increases subsequently to about $-1.6 \mathrm{mV}$. The decrease and the recovery of the amplitude are plotted in Fig. 4 versus the time after the first impalement.

We removed the TNC 26 min after the impalement and immediately re-impaled it at the same position to the same depth. The slice was stimulated as before. Now the signal recorded by the first EOSFET has the same amplitude of about $-1.5 \mathrm{mV}$ as before the withdrawal of the TNC (Fig. 4). Subsequently, the amplitude increases to about $-1.7 \mathrm{mV}$. Then the TNC was removed $36 \mathrm{~min}$ after the first impalement and re-impaled after $10 \mathrm{~min}$. Again a signal with a large amplitude is observed immediately, which remains rather stable (Fig. 4). A similar recovery of the transistor signals has been observed with four slices.
Two kinds of control experiments were performed with conventional micropipette electrodes: (i) we mounted a micropipette on the same micromanipulator as the TNC such that its tip was close to one of the EOSFETs, and impaled the assembly into a slice. We found that the responses of the transistor and of the microelectrode were almost iden-
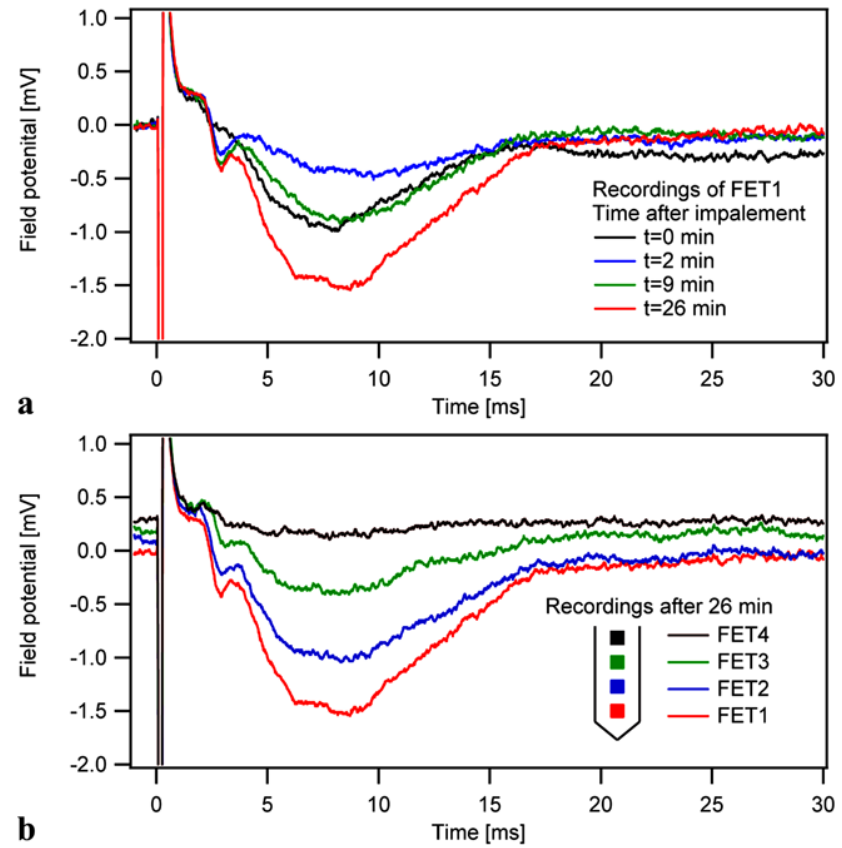

Fig. 3 Transistor recordings in stratum radiatum of CA1 upon stimulation of the Schaffer collaterals. (A) Recordings of transistor FET1 at four different times after the impalement to a depth of about $200 \mu \mathrm{m}$ in a slice with a thickness of $800 \mu \mathrm{m}$. After the stimulation artifact, negative local field potentials are recorded due to excitatory synaptic current. Their amplitude decreases within the first few minutes and subsequently increases. (B) Recordings of all four transistors 26 min after the impalement. The amplitude is high for transistor FET1 and lower for the other transistors that are closer to the surface of the slice and in the bath, respectively

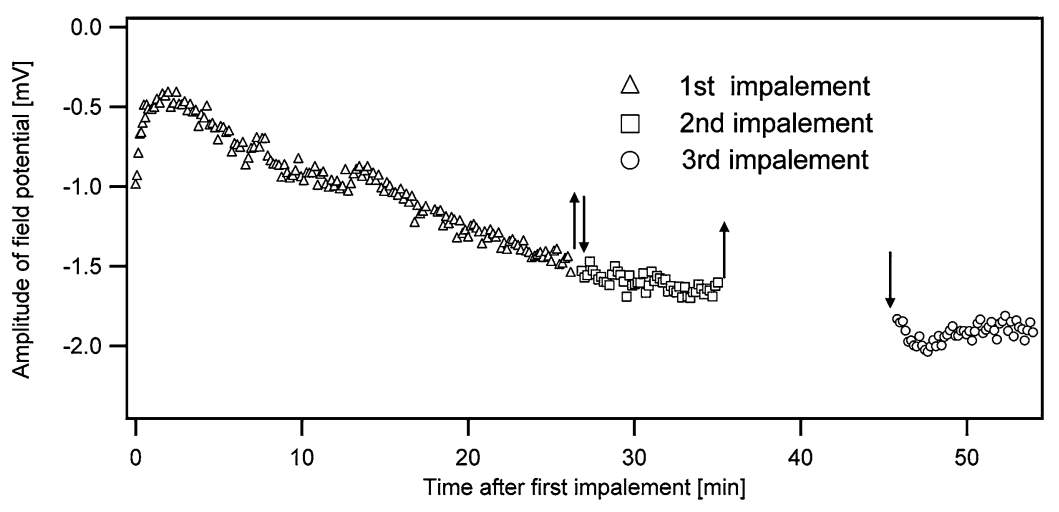

Fig. 4 Amplitude of transistor recordings in stratum radiatum of CA1 (FET1 at a depth of $200 \mu \mathrm{m}$ ) versus time after the first impalement of a TNC. The amplitude of the negative signal decreases within the first few minutes and subsequently increases. Upon the withdrawal of the
TNC after 26 min and re-impalement at the same place, the enhanced amplitude is attained immediately. After another withdrawal at $36 \mathrm{~min}$ and a re-impalement after an interval of $10 \mathrm{~min}$, the high amplitude is also observed without delay 
tical. The result confirms that a calibrated EOSFET probes the local field potential [14]. In addition, the result shows that the recovery of the transistor signal is not due to processes at the surface of the EOSFET but to the dynamics of the TNC/tissue contact. (ii) We impaled a micropipette electrode without TNC at the same speed $(500 \mu \mathrm{m} / \mathrm{s})$ into a slice. In that case, a large signal amplitude around $-2 \mathrm{mV}$ was recorded immediately after the impalement and remained constant. The result indicates that the small amplitude of transistor recording after impalement must be assigned to the interaction of the relatively massive TNC with the tissue, and it confirms that the recovery is related with an annealing of the TNC/tissue contact.

\subsection{Profile of field potential}

In the experiment described in Fig. 3, we recorded the response of all four transistors of the TNC. The recordings at a time of $26 \mathrm{~min}$ after the fast impalement are shown in Fig. 3B. The shapes of the signals are rather similar. However, the amplitudes are lower for the transistors that are closer to the surface of the slice. We studied the profile of the transistor response in more detail. After the fast impalement of the TNC to a depth of $200 \mu \mathrm{m}$ of the first ESOFET and after a recording time of about $60 \mathrm{~min}$ (see Fig. 4), the TNC was impaled across the whole slice, kept in that position for 30 min and then completely withdrawn. Then the TNC was impaled, withdrawn and impaled in steps of $20 \mu \mathrm{m}$. At each height it was held for $40 \mathrm{~s}$, the slice was stimulated three times and the three recordings were averaged for each transistor. The profile of the signal amplitudes during the second re-impalement is plotted in Fig. 5 versus the distance of the transistors from the bottom of the slice. The amplitude is largest when a transistor is near the center of the slice and small when it approaches the upper or lower surface of the slice. A similar result was obtained with four different slices.

The distinct profile of the transistor signals is not due to the TNC/tissue contact, but reflects the particular boundary conditions of a brain slice. For illustration, let us describe the slice as a volume conductor with a thickness $h=800 \mu \mathrm{m}$ and a resistivity $\rho=300 \Omega \mathrm{cm}$ [24]. At a current source density $j$, the curvature of the field potential is $\mathrm{d}^{2} \varphi / \mathrm{d} z^{2}=-\rho j$ [25]. With the agar layer and the bath at ground potential, the electrical boundary conditions are $\varphi(z=0)=0$ and $\varphi(z=h)=0$. For a homogeneous current source density, there is a parabolic profile of the field potential $\varphi(z)$ with a maximum $\varphi^{\max }=j \rho h^{2} / 8$ in the center of the slice. It corresponds to the profile of Fig. 5. When we insert the experimental value $\varphi^{\max } \approx-2 \mathrm{mV}$, we obtain a current source density $j \approx-10 \mu \mathrm{A} / \mathrm{mm}^{3}$ that is in the expected order of magnitude [26, 27]. Deviations from a parabola in Fig. 5 are due to the layers of damaged tissue on both sides of the slice $(\sim 100 \mu \mathrm{m})$ [14] and to a finite

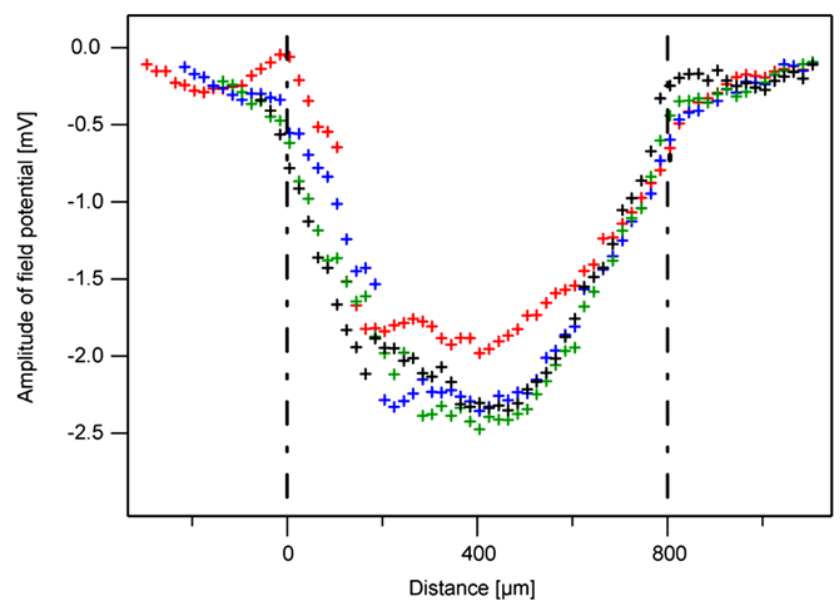

Fig. 5 Profile of transistor recordings across a hippocampus slice in stratum radiatum of the $\mathrm{CA} 1$ region. The signals are recorded during a stepwise re-impalement of a TNC after previous impalements at the same position. For details see text. The amplitude of the transistor signals (colors as in Fig. 3B) is plotted versus the distance of the transistors from the bottom of the slice. The dashed lines mark the surfaces of the slice

resistance $(\sim 50 \Omega \mathrm{cm})$ of the bath electrolyte. Variations of the profile for different transistors may be assigned to the TNC/tissue interfacing.

\section{Conclusion}

With the prototype of a transistor needle chip (TNC), the direct interfacing of field-effect transistors and intact brain tissue has been implemented. The transistor signal corresponds to a local field potential as recorded by a micropipette electrode. A profile of the signals across the slice is due to the particular boundary condition of a brain slice with its surround on ground potential. A striking issue of the experiments is the recovery of the transistor signals after the impalement of the needles. The concomitant consolidation of the tissue/chip contact must be assigned to a structural reorganization of the tissue around the rather thick prototype needle. It will be most instructive to elucidate the histology of that process.

The experiments with the TNC in a brain slice are the basis for applications in the brain of living animals. There the long-term features of recording must be addressed in detail. The inert and homogeneous surface of the chips formed by $\mathrm{TiO}_{2}$ will provide chemical stability and biocompatibility. The present study is a starting point for the development of TNCs with a multi-transistor array (MTA) $[28,29]$, which will enable us to record the patterns of local field potentials and of single unit recordings in the brain. Analogous capacitor needle chips (CNCs) may be fabricated for stimulation.

Acknowledgements We thank Eva Tois (ASM, Helsinki) for the atomic layer deposition of $\mathrm{TiO}_{2}$, Helge Vogl for support with clean 
room technology and Christian Stangl for help with the brain slices. In part, the project was supported by the European Union (project CyberRat).

Open Access This article is distributed under the terms of the Creative Commons Attribution Noncommercial License which permits any noncommercial use, distribution, and reproduction in any medium, provided the original author(s) and source are credited.

\section{References}

1. J.P. Donoghue, Nat. Neurosci. 5, 1085 (2002)

2. A.B. Schwartz, X.T. Cui, D.J. Weber, D.W. Moran, Neuron 52, 205 (2006)

3. M.A. Lebedev, M.A.L. Nicolelis, Trends Neurosci. 29, 536 (2006)

4. J.D. Kralik, D.F. Dimitrov, D.J. Krupa, D.B. Katz, D. Cohen, M.A.L. Nicolelis, Methods 25, 121 (2001)

5. M.A.L. Nicolelis, D. Dimitrov, J.M. Carmena, R. Crist, G. Lehew, J.D. Kralik, S.P. Wise, Proc. Natl. Acad. Sci. USA 100, 11041 (2003)

6. K.D. Wise, J.B. Angell, A. Starr, IEEE Trans. Biomed. Eng. 17, $238(1970)$

7. R.A. Normann, E.M. Maynard, P.J. Rousche, D.J. Warren, Vis. Res. 39, 2577 (1999)

8. G. Ensell, D.J. Banks, P.R. Richards, W. Balachandran, D.J. Ewins, Med. Biol. Eng. Comput. 38, 175 (2000)

9. C.A. Miller, B.K. Robinson, J.F. Hetke, P.J. Abbas, K.V. Nourski, Hear Res. 198, 48 (2004)
10. L.R. Hochberg, M.D. Serruya, G.M. Friehs, J.A. Mukand, M. Saleh, A.H. Caplan, A. Branner, D. Chen, R.D. Penn, J.P. Donoghue, Nature 442, 164 (2006)

11. M. Voelker, P. Fromherz, Small 1, 206 (2005)

12. I. Schoen, P. Fromherz, J. Neurophysiol. 100, 346 (2008)

13. M. Hutzler, P. Fromherz, Eur. J. Neurosci. 19, 2231 (2004)

14. C. Stangl, P. Fromherz, Eur. J. Neurosci. 27, 958 (2008)

15. R. Weis, P. Fromherz, Phys. Rev. E 55, 877 (1997)

16. R. Weis, B. Müller, P. Fromherz, Phys. Rev. Lett. 76, 327 (1996)

17. F. Wallrapp, P. Fromherz, J. Appl. Phys. 99, 114103 (2006)

18. A. Reisman, M. Berkenblit, S.A. Chan, F.B. Kaufman, D.C. Green, J. Electrochem. Soc. 126, 1406 (1979)

19. T. Syau, B.J. Baliga, R.W. Hamaker, J. Electrochem. Soc. 138, 3076 (1991)

20. M.J. Sowa, M.E. Littau, V. Pohray, J.L. Cecchi, J. Vac. Sci. Technol. 18, 2122 (2000)

21. R. Dingledine, Brain Slices (Plenum, New York, 1984)

22. M. Korte, O. Griesbeck, C. Gravel, P. Carroll, V. Staiger, H. Thoenen, T. Bonhoeffer, Proc. Natl. Acad. Sci. USA 93, 12547 (1996)

23. P. Anderson, S.H. Sundberg, O. Sveen, H. Wigström, Nature 266, 736 (1977)

24. J. Holsheimer, Exp. Brain Res. 67, 402 (1987)

25. U. Mitzdorf, Physiol. Rev. 65, 37 (1985)

26. J.S. Taube, P.A. Schwartzkroin, J. Neurosci. 8, 1645 (1988)

27. J. Brankack, M. Stewart, S.E. Fox, Brain Res. 615, 310 (1993)

28. M. Hutzler, A. Lambacher, B. Eversmann, M. Jenkner, R. Thewes, P. Fromherz, J. Neurophysiol. 96, 1638 (2006)

29. A. Lambacher, V. Vitzthum, R. Zeitler, M. Eickenscheidt, B. Eversmann, R. Thewes, P. Fromherz, Appl. Phys. A 102, 1 (2011) 